\title{
Angiotensin II type I receptor antagonists in the treatment of hypertension in elderly patients: focus on patient outcomes
}

This article was published in the following Dove Press journal:

Patient Related Outcome Measures

19 January 2011

Number of times this article has been viewed

\author{
Artavazd Tadevosyan' \\ Eric J MacLaughlin ${ }^{2}$ \\ Vardan T Karamyan ${ }^{3}$ \\ 'Departments of Medicine, Montreal \\ Heart Institute and Université de \\ Montréal, Montreal, QC, Canada; \\ ${ }^{2}$ Department of Pharmacy Practice, \\ ${ }^{3}$ Department of Pharmaceutical \\ Sciences, School of Pharmacy, Texas \\ Tech University Health Sciences \\ Center, Amarillo, TX, USA
}

\begin{abstract}
Hypertension in the elderly is one of the main risk factors of cardiovascular and cerebrovascular diseases. Knowledge regarding the mechanisms of hypertension and specific considerations in managing hypertensive elderly through pharmacological intervention(s) is fundamental to improving clinical outcomes. Recent clinical studies in the elderly have provided evidence that angiotensin II type 1 ( $\mathrm{AT}_{1}$ ) receptor antagonists can improve clinical outcomes to a similar or, in certain populations, an even greater extent than other classical arterial blood pressure-lowering agents. This newer class of antihypertensive agents presents several benefits, including potential for improved adherence, excellent tolerability profile with minimal first-dose hypotension, and a low incidence of adverse effects. Thus, $\mathrm{AT}_{1}$ receptor antagonists represent an appropriate option for many elderly patients with hypertension, type 2 diabetes, heart failure, and/or left ventricular dysfunction.
\end{abstract}

Keywords: angiotensin II, ARB, cardiovascular disease, antihypertensive therapy, elderly

\section{Introduction}

Hypertension is a crucial, modifiable risk factor for cardiovascular and cerebrovascular diseases and remains a leading cause of preventable morbidity and mortality in most developed countries. ${ }^{1}$ In 2000 , it was estimated that $26 \%$ of adults worldwide (972 million) had hypertension, and this number is expected to increase to $29.2 \%$ (1.56 billion) by $2025 .^{2}$ The incidence of hypertension increases worldwide with the progression of an aging population, making it the most dominant and common morbid condition in the elderly. In the Framingham Heart Study, it was estimated that normotensive adults aged 55-65 years had more than a 90\% lifetime risk of developing hypertension during the rest of their life. ${ }^{3}$ Hence, age is considered to be the most crucial causative factor for hypertension and cardiovascular death. ${ }^{4}$

Clinical trials have demonstrated that treatment of hypertension in the elderly prevents heart failure, reduces the risk of stroke, and prolongs life. ${ }^{5-9}$ Notably, (patho) physiological modifications linked to both aging and high arterial blood pressure must be taken into consideration when choosing an appropriate blood pressure-lowering treatment for the elderly. ${ }^{10}$ For example, characteristic changes that occur in the elderly with high blood pressure are decreased cardiac output, increased peripheral resistance due to age-related decline of vascular compliance, impaired baroreceptor sensitivity, and reduced intravascular volume. ${ }^{11,12}$

Major benefits of antihypertensive therapy are related to lowering and controlling of blood pressure through lifestyle modification(s) and drug therapy. ${ }^{13,14}$ Therapeutic management of hypertension in the elderly includes five main classes of drugs that
Correspondence: Vardan T Karamyan Department of Pharmaceutical Sciences, School of Pharmacy, Texas Tech University Health Sciences Center, Room 408, 1300 Coulter Street, Amarillo, TX 79106, USA

Tel + I 8063564015 ext 286

Email vardan.karamyan@ttuhsc.edu submit your manuscript | www.dovepress.com

Dovepress

DOI: 10.2147/PROM.S8384 
have been clinically studied and successfully used over several decades. These classes include angiotensin II type 1 $\left(\mathrm{AT}_{1}\right)$ receptor antagonists (angiotensin receptor blockers or ARBs), angiotensin-converting enzyme inhibitors (ACEIs), $\beta$-adrenergic receptor antagonists ( $\beta$-blockers), calcium channel blockers, and thiazide diuretics. ${ }^{15}$ The diversity of these medications has fuelled debates regarding which class of antihypertensive is most suitable as a first-line therapeutic agent. ${ }^{16}$ In addition, although the Seventh Report of the Joint National Committee on Prevention, Detection, Evaluation, and Treatment of High Blood Pressure (JNC 7) recommends two-drug combinations in patients who have significantly elevated blood pressure (ie, $20 \mathrm{~mm} \mathrm{Hg}$ above their systolic blood pressure goal and/or $10 \mathrm{~mm} \mathrm{Hg}$ above diastolic blood pressure goal), this recommendation may not be prudent in older patients due to the risk of orthostatic hypotension. ${ }^{17}$ In addition, multiple drug therapies may increase the risk of other undesirable adverse effects and problems with drug adherence, which are important issues of consideration in pharmacotherapy of the elderly. Medications used in the elderly should ideally meet the following criteria: i) once- or twice-daily administration, ii) low incidence of side effects, and iii) low cost with available equivalent drugs of similar effectiveness. ${ }^{18}$

The purpose of this review is to discuss the pharmacology of angiotensin receptor antagonists, particularly as it relates to the elderly, and describe data that support the use of these agents in older hypertensive patients. Information on the use of other antihypertensive drugs in the elderly is reviewed elsewhere. ${ }^{19-22}$

\section{Overview of the use of AT, receptor antagonist in the elderly}

Angiotensin receptor antagonists act on the final step of the renin-angiotensin-aldosterone system (RAAS) by selectively blocking the $\mathrm{AT}_{1}$ receptor and preventing the effects of angiotensin II mediated by this receptor (Figure 1). Blockade of the $\mathrm{AT}_{1}$ receptor by angiotensin receptor blockers (ARBs) results in a dose-dependent fall of peripheral resistance without a significant change in the heart rate or cardiac output. ${ }^{23}$

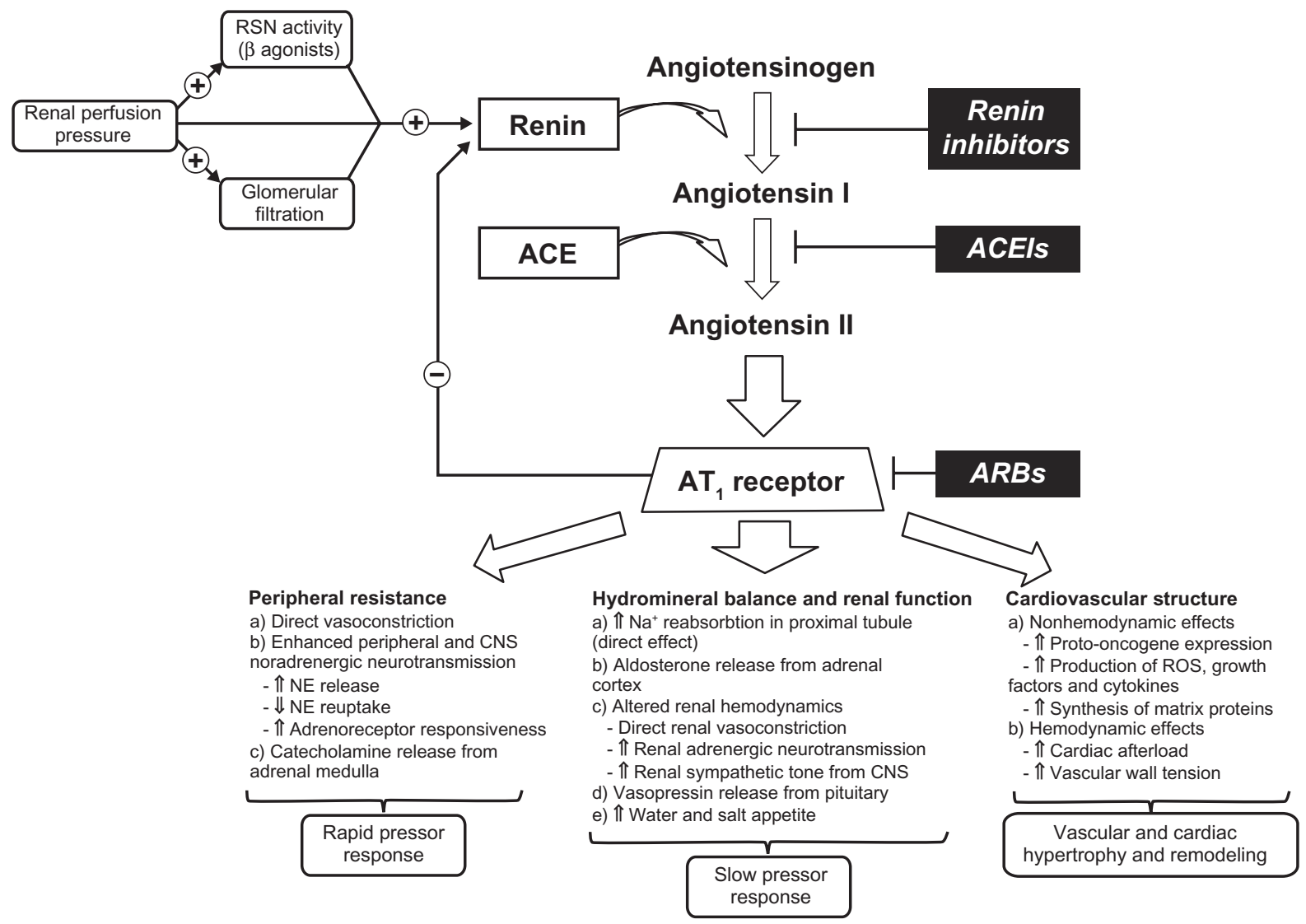

Figure I Schematic illustration of the RAAS and the main pathways by which RAAS regulates cardiovascular function. ${ }^{148,149}$

Abbreviations: ACE, angiotensin-converting enzyme; ACEls, angiotensin-converting enzyme inhibitors; ARBs, angiotensin receptor blockers; CNS, central nervous system; NE, norepinephrine; RAAS, renin-angiotensin-aldosterone system; RSN, renal sympathetic nerve; ROS, reactive oxygen species. 
ARBs offer a variety of advantages for elderly hypertensive patients; they have excellent tolerability, have minimal drug interactions, and may be dosed once daily. ${ }^{24}$ Because of these factors, medication adherence may also be optimized, which is particularly important considering that polypharmacy is common among hypertensive elderly. ${ }^{25}$

The integral role of circulatory RAAS in maintaining normal hemodynamic status is well documented. ${ }^{26-28}$ It is also known that activity of this system declines with age, which is mainly due to reduction of renin activity and plasma aldosterone concentrations. ${ }^{29,30}$ Notably, increased activity of RAAS has not proven to be the major cause of primary (essential) hypertension, unlike in progression of atherosclerosis and vascular disease, where angiotensin II, the main effector molecule of the system, is highly implicated. ${ }^{31}$ Most physiological actions of angiotensin II, including smooth muscle contraction, release of aldosterone, and cell growth and proliferation, are due to activation of the $\mathrm{AT}_{1}$ receptor. ${ }^{32}$ In addition, excessive binding of angiotensin II to this receptor is one of the main pathological mechanisms leading to sustained vasoconstriction, cardiac hypertrophy, fibrosis, endothelial dysfunction, heart failure, arrhythmias, and atherogenesis. ${ }^{33-38}$

The first therapeutic agents that targeted the RAAS in treatment of hypertension were ACEIs, which were developed more than 30 years ago. ${ }^{39}$ ACEIs have been demonstrated to be very effective in the treatment of hypertension, as well as other cardiovascular and renal diseases. ${ }^{40,41}$ However, some of the side effects of ACEIs and their inability to block alternative pathways of angiotensin II generation (eg, chymase in the heart) were reasons for the development of $\mathrm{AT}_{1}$ receptor antagonists, which specifically block the effects of angiotensin II mediated through the $\mathrm{AT}_{1}$ receptor. ${ }^{42}$

A common side effect of ACE inhibitors is cough. Although the mechanism(s) behind ACEI-induced cough is not fully understood, it may involve elevated levels of bradykinin and stimulation of vagal $\mathrm{C}$ fibers. ${ }^{43}$ The frequency of cough varies among different patient populations. The rate appears to be around $10 \%$ in white patients but may be as high as $44 \%$ in Asian patients. ${ }^{44}$ Cough is more common among women than men, tends to be dry, is mildly annoying, and often requires cessation of therapy. ${ }^{45}$

Angioedema is a rare but potentially life-threatening side effect of ACEIs. ${ }^{43,46}$ It is characterized by localized swelling of the lips, mouth, tongue, throat, nose, or other parts of the face. ${ }^{43}$ The mechanism of this side effect appears to involve bradykinin and/or one of its metabolites. The rate of angioedema has been reported to be 1 per $1000(0.1 \%)$ in primarily white patients but appears to be higher in black patients. ${ }^{47,48}$

ARBs were introduced in the mid-1990s as more selective drugs for RAAS inhibition with an improved safety and tolerability profile. ${ }^{49,50}$ The first orally active selective AT receptor antagonist approved by the US Food and Drug Administration in 1995 was losartan. Over the past two decades, it has undergone extensive pharmacological and clinical investigations. ${ }^{51,52}$ This was followed by development of several other ABRs, including valsartan, irbesartan, candesartan, telmisartan, eprosartan, and olmesartan, which differ by modifications in their chemical structure and have somewhat different pharmacological properties. ${ }^{53}$

\section{Clinical studies of angiotensin AT, receptor antagonists in hypertension and related cardiovascular disorders}

ARBs are widely used for the treatment of hypertension because of well-documented safety and efficacy. A metaanalysis by the Blood Pressure Lowering Treatment Trialists' Collaboration group indicates that similar to other commonly used blood pressure-lowering regimens, various $\mathrm{AT}_{1}$ receptor blockers result in a similar reduction of total major cardiovascular events through management of elevated arterial blood pressure. ${ }^{54} \mathrm{~A}$ recent meta-analysis of 108 studies in 464,000 patients by Law et al also confirmed that all the major classes of blood pressure-lowering drugs have a similar effect on reducing coronary heart disease events and stroke for a given reduction in blood pressure. ${ }^{55}$

Heart failure and left ventricular dysfunction are two of the main outcomes of uncontrolled hypertension in elderly patients. ${ }^{56}$ Overactivation of the RAAS and the sympathetic nervous system are crucial in the pathogenesis and progression of chronic heart failure. ${ }^{57}$ For this reason, treatments targeting the RAAS, typically with an ACE inhibitor or ARB, in patients with heart failure have been shown to substantially improve mortality and morbidity. ${ }^{58-60}$

The Evaluation of Losartan in the Elderly (ELITE) trial was the first moderately long (48 weeks) randomized study comparing losartan with captopril in 722 elderly patients aged $\geq 65$ years with New York Heart Association (NYHA) class II-IV heart failure and an ejection fraction of $\leq 40 \%{ }^{61}$ After 48 weeks, patients in both groups had similar improvement in NYHA functional class compared with baseline ( $80 \%$ of losartan-treated patients vs $81 \%$ of captopril-treated 
patients), and hospitalizations were less frequent with losartan than with captopril treatment (22.2\% vs $29.7 \%)$. However, significantly more patients withdrew from captopril than from losartan $(21 \%$ vs $12 \% ; P=0.002)$, primarily due to captopril-related side effects such as cough, angioedema, and rash. Moreover, patients in the losartan group had a $46 \%$ reduction in all-cause mortality in comparison with those in the captopril group $(P=0.035)$, which was primarily due to a reduced incidence of sudden cardiac death. Notably, the reduction in mortality with ACEI or ARB treatment was not the primary endpoint of this study. As a result, a large-scale randomized trial, the Losartan Heart Failure Survival Study (ELITE II), was initiated.

ELITE II was a double-blind randomized controlled trial in 3152 patients (mean age 71 years) with NYHA class II-IV heart failure and an ejection fraction of $\leq 40 \%$ and was designed to test the superiority of losartan to captopril in improving survival and tolerability. ${ }^{62}$ After a median follow-up of 555 days, there was no significant difference in all-cause mortality (17.7\% losartan vs $15.9 \%$ captopril), sudden death $(8.2 \%$ losartan vs $6.4 \%$ captopril), or resuscitated arrests $(9.0 \%$ losartan vs $7.3 \%$ captopril). However, significantly fewer patients discontinued treatment in the losartan group because of adverse effects (9.7\% vs $14.7 \%$; $P=0.001)$ or cough $(0.3 \%$ vs $2.7 \%)$.

The Valsartan Heart Failure Trial was the first large trial to study the effects of additional ARB treatment on standard heart failure therapy. ${ }^{63}$ In this study, 5010 patients (mean age 62.7 years) with NYHA class II-IV and an ejection fraction of $\leq 40 \%$ were randomized to receive valsartan or placebo in addition to standard therapy. After an average follow-up of 23 months, there was no difference in overall mortality between the two groups (19.7\% valsartan vs $19.4 \%$ placebo). However, valsartan treatment was associated with a reduced risk for a combined endpoint of mortality plus morbidity, cardiac arrest with resuscitation, hospitalization for heart failure, or intravenous inotropic or vasodilator therapy $(28.8 \%$ valsartan vs $32.1 \%$ placebo; $P=0.009$ ). This reduction was mainly driven by a $24 \%$ reduction in risk of hospitalization for heart failure in the valsartan group. ${ }^{63}$ Notably, a subgroup of 366 patients (7\%) in this study were not treated with an ACEI, which allowed comparison of valsartan as monotherapy with placebo. ${ }^{64}$ The results from this subgroup indicated a significant reduction in both all-cause mortality $(30 \%$; $P=0.01)$ and all-cause hospitalizations $(45 \% ; P=0.0002)$. Exclusion of this subgroup of patients made the observed overall reduction in the combined endpoint of mortality and morbidity no longer significant for the whole study.
The Candesartan in Heart Failure Assessment of Reduction in Mortality and Morbidity (CHARM) trials compared candesartan with placebo (in parallel, double-blind, randomized controlled studies) in three distinct populations with NYHA class II-IV heart failure. Patients were randomized to one of three trials: those who were not receiving ACEIs because of intolerance (CHARM-Alternative), patients with similar symptoms who were already receiving an ACEI (CHARM-Added), and patients with left ventricular ejection fractions $\geq 40 \%$ (CHARM-Preserved). ${ }^{65}$ The CHARMAlternative trial included 2028 patients (average age 66.5 years). ${ }^{6}$ During a median follow-up of 33.7 months, the addition of candesartan to patients who were not on an ACEI was associated with a $30 \%$ decrease in risk of cardiovascular death or hospital admissions for heart failure compared with placebo (covariate adjusted hazards ratio, 0.70; $P<0.0001$ ). In addition, study drug withdrawal rates were similar in both groups (30\% vs 29\%). In the CHARM-Added trial, the addition of candesartan to ongoing ACEI therapy was assessed in 2548 patients (mean age 64 years) with heart failure. After a median follow-up of 41 months, there was a significant reduction in cardiovascular death or hospital admissions for heart failure in the candesartan group compared with placebo (38\% vs 42\%; unadjusted hazard ratio [HR] 0.85; $P=0.011) .{ }^{68}$ However, study-drug withdrawal rates due to adverse events or laboratory abnormalities were significantly higher in the candesartan group compared with placebo (24.2\% vs $18.3 \%$; $P=0.0003)$. The CHARM-Preserved trial assessed the effect of candesartan in 3023 patients (mean age 67.1 years) with a preserved ejection fraction (ie, $\geq 40 \%$ ). At the end of 36.6 months, there was no difference in cardiovascular death (170 vs 170), but there were fewer hospital admissions for heart failure with candesartan (230 vs $279 ; P=0.017) .{ }^{67}$ Composite outcomes that included nonfatal myocardial infarction and nonfatal stroke also showed similar results to the primary outcomes in both groups $(25.6 \%$ candesartan vs $28.4 \%$ placebo; $P=0.078$; covariate adjusted HR 0.86 ; $P=0.037)$. Overall results of the CHARM trials indicate that in patients with heart failure and left ventricular dysfunction, candesartan is an effective alternative to ACEIs in patients not able to tolerate an ACEI. In addition, routine use of an $\mathrm{ARB}$ in addition to standard therapy, which includes ACEIs, or in elderly patients with heart failure and preserved left ventricular function does not appear justified due to a lack of efficacy and/or additional side effects.

The Optimal Trial in Myocardial Infarction with Angiotensin II Antagonist Losartan (OPTIMAAL) was another large randomized trial that studied the superiority of losartan 
to captopril in decreasing all-cause mortality in high-risk patients. ${ }^{69}$ In the study, 5477 patients (mean age 67.4 years) who had confirmed acute myocardial infarction and heart failure during the acute phase or a new $Q$ wave anterior infarction or reinfarction were randomly assigned and titrated to a target dose of losartan (50 mg once daily) or captopril (50 mg three times daily) as tolerated. After an average follow-up of 2.7 years, there were no significant differences in all-cause mortality (18.2\% vs $16.4 \%)$, sudden death or resuscitated arrests ( $8.7 \%$ vs $7.4 \%)$, or nonfatal reinfarctions $(14.0 \%$ vs $13.9 \%)$ between the two treatment groups. Similar to previous findings, losartan was better tolerated than captopril with fewer patient withdrawals ( $17 \%$ vs $23 \% ; P<0.0001)$.

The Valsartan in Acute Myocardial Infarction trial (VALIANT) was a double-blind, randomized study that compared the effects of valsartan in patients who had suffered a recent myocardial infarction. ${ }^{70}$ In this study, 17,703 patients (mean age 64 years) were randomized to receive valsartan, valsartan plus captopril, or captopril in addition to standard therapy within 0.5-10 days after an acute myocardial infarction. After a median follow-up of 24.7 months, there were no differences in mortality or fatal and nonfatal cardiovascular events between the three groups (valsartan group $19.9 \%$; valsartan plus captopril group $19.3 \%$; captopril group $19.5 \%$ ). The HR for death in the valsartan group as compared with the captopril group was $1.00(97.5 \%$ confidence internal [CI] $0.90-1.11 ; P=0.98)$, and the HR for death in the valsartan plus captopril group as compared with the captopril group was 0.98 (97.5\% CI 0.89-1.09; $P=0.73)$. Notably, the valsartan plus captopril group had the most drug-related adverse effects compared with the other two groups (34.8\% valsartan plus captopril group vs $29.4 \%$ valsartan group vs $28.4 \%$ captopril group; $P<0.05$ for differences between the captopril group).

The Ongoing Telmisartan Alone and in Combination with Ramipril Global Endpoint Trial (ONTARGET) involved 25,620 patients (mean age 66.4 years) with established coronary artery, peripheral vascular or cerebrovascular disease, or diabetes with end-organ damage, who after a 3-week single-blind run-in period underwent double-blind randomization with the ACEI ramipril $(\mathrm{n}=8576)$, ARB telmisartan $(n=8542)$, or both drugs combined $(n=8502) .{ }^{71}$ The primary purpose of this study was to determine whether telmisartan was superior or inferior to ramipril and whether the combination was superior to ramipril monotherapy in reducing morbidity and mortality in patients at high risk of having a vascular event or diabetes but without heart failure. After a median follow-up of 56 months, there was no statistically significant difference in death from cardiovascular causes, myocardial infarction, and stroke or in hospitalization for heart failure between the treatment groups (16.5\% ramipril vs $16.7 \%$ telmisartan vs $16.3 \%$ combination). Compared with ramipril, telmisartan was associated with lower rates of cough $(1.1 \%$ vs $4.2 \% ; P<0.001)$ and angioedema $(0.1 \%$ vs $0.3 \%$; $P=0.01)$ and higher rates of hypotensive symptoms $(1.7 \%$ vs $2.6 \% ; P<0.001)$. In addition, compared with ramipril alone, the combination was associated with more hypotensive symptoms $(1.7 \%$ vs $4.8 \% ; P<0.001)$, syncope $(0.2 \%$ vs $0.3 \% ; P=0.03)$, diarrhea $(0.1 \%$ vs $0.5 \% ; P<0.001)$, and renal dysfunction $(0.7 \%$ vs $1.1 \% ; P<0.001)$. Thus, although telmisartan was demonstrated to be noninferior to ramipril in reducing cardiovascular events in patients at high risk of an event, the combination of an ACEI and an ARB did not result in additive benefits and was associated with increased side effects.

The Telmisartan Randomized Assessment Study in ACE Intolerant Subjects With Cardiovascular Disease (TRANSCEND) was one of the components of ONTARGET, which involved 5926 high-risk patients who exhibited clinical intolerance to ACEIs. ${ }^{72}$ After a 3-week run-in period, patients were randomized to receive telmisartan $(n=2954)$ or placebo $(\mathrm{n}=2972)$, and the same primary outcome as in ONTARGET was assessed. After a median follow-up of 56 months, there was no difference in the primary outcome of cardiovascular death, myocardial infarction, stroke, or hospitalization for heart failure between telmisartan and placebo (HR 0.92; 95\% CI $0.81-1.05 ; P=0.216)$. The composite of cardiovascular death, myocardial infarction, or stroke was lower in telmisartan group compared with placebo after adjustment for multiplicity of comparisons and overlap with the primary outcome (relative risk 0.87 ; $95 \%$ CI $0.76-1.00$; unadjusted $P=0.048$ vs adjusted $P=0.068)$. Telmisartan was associated with a decreased risk of hospitalization for cardiovascular reasons compared with placebo $(30.3 \%$ vs $33.0 \% ; P=0.025)$.

The findings of these major clinical outcome studies on ARBs are summarized in Table 1. Overall, the major clinical outcomes of these trials, which primarily involved elderly patients, demonstrate that ARBs reduce cardiovascular events in patients, including those who are at high risk, equivalent to ACEIs and that this class of drugs can be considered as a first-line therapy in those intolerant to ACEI therapy.

\section{Use of angiotensin II AT, receptor antagonists in type 2 diabetes}

Diabetes is rapidly increasing worldwide in all patient groups, including the elderly. ${ }^{73}$ It is estimated that $50 \%$ of patients 


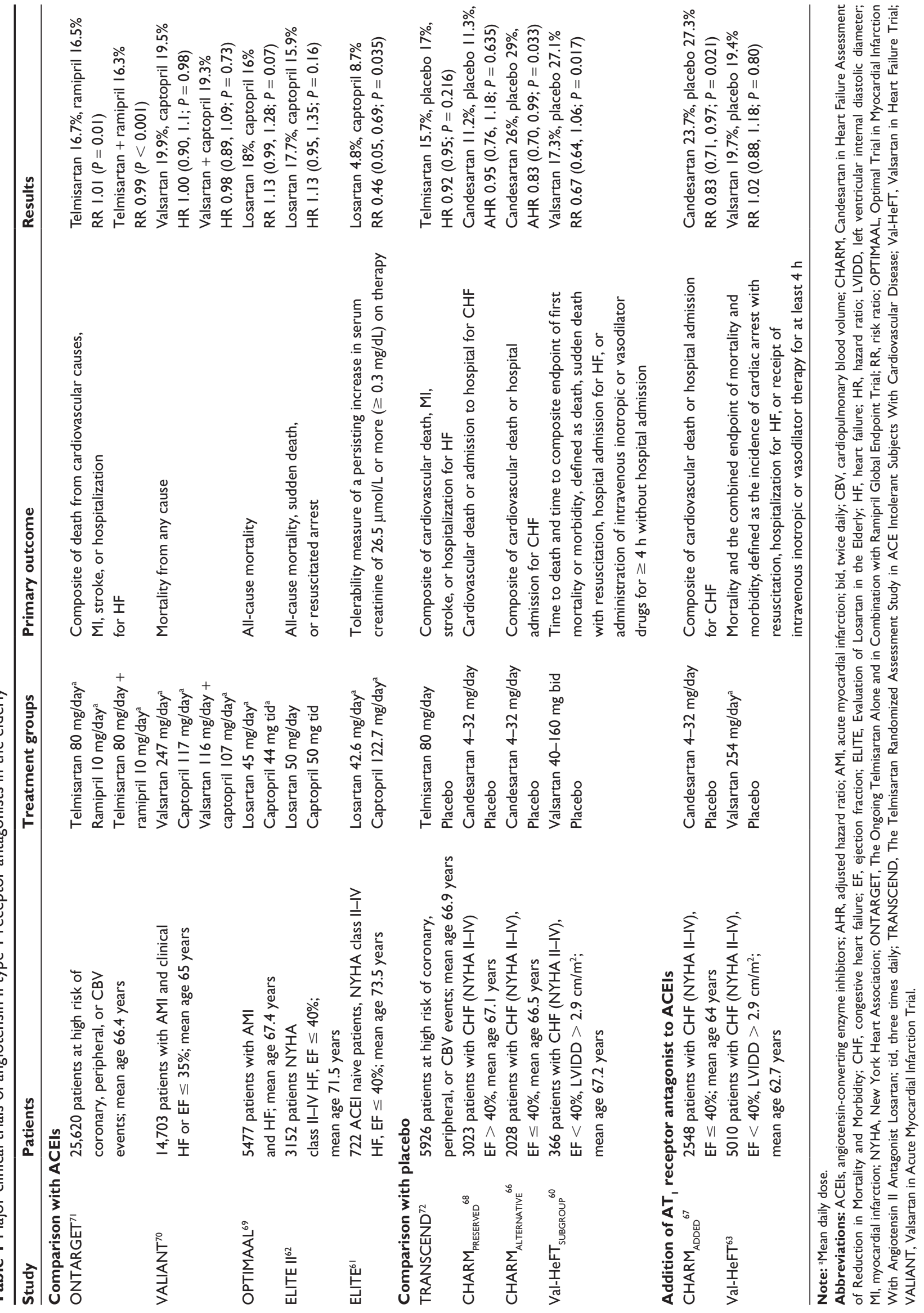


with diabetes suffer from hypertension, and this number is even higher in the elderly. ${ }^{74}$ Additionally, chronic kidney disease (CKD) is a major cause of morbidity and mortality in patients with diabetes, and the role of the RAAS in the development of CKD in patients with diabetes has been well documented. ${ }^{75,76}$ A number of clinical studies, including Irbesartan in Type 2 Diabetes (IRMA 2), ${ }^{77}$ the Irbesartan Type 2 Diabetic Nephropathy Trial (IDNT), ${ }^{78}$ Reduction in End Points in NIDDM with the Angiotensin II Antagonist Losartan (RENAAL), ${ }^{79}$ and Microalbuminuria Reduction with Valsartan (MARVAL), ${ }^{80}$ have established the superior efficacy of $\mathrm{AT}_{1}$ receptor antagonists over conventional, non-ACEI, blood pressure-lowering agents in patients with type 2 diabetes and renal insufficiency. Importantly, these studies have highlighted that the renoprotective effects of $\mathrm{AT}_{1}$ receptor antagonists are not solely due to a reduction of blood pressure. Instead, multiple actions of ARBs appear to be responsible for beneficial effects of these agents in diabetes. ${ }^{81}$ In fact, blockade of angiotensin II binding to the $\mathrm{AT}_{1}$ receptor results in improvement of insulin and glucose metabolism at different levels, including an improvement in insulin secretion and peripheral insulin responses. ${ }^{82,83}$ Moreover, angiotensin II signaling is implicated in vascular injury associated with diabetes, and inhibition of $\mathrm{AT}_{1}$ receptors attenuates these responses markedly, including the diabetic proinflammatory state. ${ }^{84}$

These molecular mechanisms can be translated into clinical settings. A recent meta-analysis that combined 22 clinical trials with 143,153 patients treated with different antihypertensive agents confirmed that ARBs potently decrease the relative risk for new onset of diabetes by $38 \%$ compared with diuretics. ${ }^{85}$ In these studies, treatment of patients with diabetes with ARBs resulted in a substantial reduction of cardiovascular endpoints, underlining that blockade of $\mathrm{AT}_{1}$ receptors may potentially provide not only antidiabetic action but also cardiovascular protection in diabetes. As a result, $\mathrm{AT}_{1}$ receptor antagonists are recommended as a first-line therapy in patients with hypertension and concomitant type 2 diabetes and/or CKD. ${ }^{13,86}$

\section{Efficacy and tolerability studies of ARBs in elderly patients}

The Losartan Intervention for Endpoint Reduction in Hypertension Study (LIFE) was one of the first clinical trials to demonstrate that $\mathrm{AT}_{1}$ receptor antagonists may have greater benefits than other antihypertensives in high-risk patients, including the elderly. ${ }^{87}$ In this double-blind trial, 9193 patients aged between 55 and 80 years (mean age 66.7 years) with hypertension and left ventricular hypertrophy on ECG were randomized to either once-daily losartan or atenolol. After a mean follow-up of 4 years, the primary composite endpoint of cardiovascular morbidity and mortality, which included stroke, myocardial infarction, and cardiovascular death, was reduced $13 \%$ more in losartan-treated patients compared with the atenolol-treated group $(P=0.021)$. In addition, the incidence of fatal or nonfatal stroke was $25 \%$ lower in the losartan group compared with the atenolol group $(P=0.001)$. There were no statistically significant differences in coronary events between both groups (17\% vs $15 \%$ for losartan and atenolol, respectively). Importantly, the extent of a reduction of mean arterial blood pressure was essentially identical in the treatment groups (102.2 vs $102.4 \mathrm{~mm} \mathrm{Hg}$ for losartan and atenolol, respectively). In a subgroup of 1195 patients with diabetes, losartan decreased the primary composite endpoint by $24 \%$ (18\% vs $23 \%$ for losartan and atenolol, respectively; $P=0.031)$. In addition, there was a statistically significant reduction in cardiovascular and total mortality in the losartan group ( $P=0.028$ and $P=0.002$, respectively).$^{88}$ Notably, when stratified by race (black and nonblack groups), there was a lower risk for the primary endpoint with atenolol versus losartan (HR 1.67 for losartan vs atenolol; $P=0.033$ ). ${ }^{89,90}$

The Study of Cognition and Prognosis in the Elderly (SCOPE) was a prospective, double-blind, randomized, parallel-group study that compared candesartan with placebo in 4964 elderly hypertensive patients aged between 70 and 89 years. The primary goal of this study was to assess whether treatment with candesartan in elderly subjects with mildly to moderately elevated blood pressure results in a reduction of cardiovascular events, cognitive decline, and dementia. ${ }^{91}$ During a mean follow-up of 44.6 months, there was no difference in the reduction of mean arterial blood pressure with candesartan versus placebo (145.2 vs $148.5 \mathrm{~mm} \mathrm{Hg}$, respectively). However, despite no significant difference in arterial blood pressure, candesartan was associated with a $27.8 \%$ reduction in nonfatal stroke $(P=0.04)$ and a $23.6 \%$ reduction in all strokes $(P=0.056)$ compared with placebo. There was no statistically significant difference in myocardial infarction ( $1.9 \%$ candesartan vs $2.0 \%$ placebo) or cardiovascular mortality $(15.6 \%$ candesartan vs $16.6 \%$ placebo). An analysis including only patients with isolated systolic hypertension, a type of hypertension very common in the elderly, showed a $40 \%$ reduction in stroke in patients treated with candesartan $(P=0.05) .{ }^{92,93}$

The Valsartan Antihypertensive Long-term Use Evaluation (VALUE) trial was a double-blind, randomized, parallel-group study in 15,245 patients aged above 50 years 
(mean age 67.2 years) suffering from hypertension and additional diseases conferring high risk of cardiac events, where the effects of an ARB therapy (valsartan 80-160 mg/day) were compared with calcium channel blocker therapy (amlodipine 5-10 mg/day). ${ }^{94}$ During the first year, amlodipine reduced the mean arterial blood pressure by an extra $1.5 / 1.3 \mathrm{~mm} \mathrm{Hg}$ compared with valsartan $(P<0.001)$. However, over a mean follow-up of 4.2 years, there was no statistically significant difference between the groups with regard to cardiac mortality ( $4.0 \%$ vs $4.0 \%)$, morbidity $(7.7 \%$ vs $7.6 \%)$, or overall mortality $(11.0 \%$ vs $10.8 \%)$. There was a trend toward a higher incidence of stroke ( $4.2 \%$ valsartan and $3.7 \%$ amlodipine; $P=0.08)$ and myocardial infarction (4.8\% valsartan vs $4.1 \%$ amlodipine; $P=0.02)$ and a decreased incidence of heart failure $(4.6 \%$ valsartan vs $5.3 \%$ amlodipine; $P=0.12$ ) in the valsartan group. Additionally, it was shown that valsartan therapy reduced the onset of diabetes in patients by $23 \%(P=0.0001) .{ }^{94}$ Similar findings were reported in other clinical trials with $\mathrm{AT}_{1}$ receptor antagonists, ${ }^{65,95}$ which may represent a long-term benefit of ARBs that is probably not easily observable in short-term clinical studies monitoring cardiovascular outcomes. ${ }^{65,95}$

Clinical trials investigating the efficacy of $\mathrm{AT}_{1}$ receptor antagonists have reported adverse event rates similar to those seen with placebo and considerably lower than those in groups treated with ACEIs. ${ }^{62,96-98}$ Comparable tolerability profiles were identified in the elderly population, with relatively few undesirable effects reported in patients receiving ARBs compared with ACEIs. ${ }^{61}$

Undesirable effects of $\mathrm{AT}_{1}$ receptor antagonists that have been reported include fatigue, dizziness, headache, hyperkalemia, hypotension, and acute renal insufficiency in predisposed patients or those at risk. ${ }^{99,100}$ Hyperkalemia is increased primarily in patients already receiving therapy that targets the RAAS (eg, concomitant ACEI use or aldosterone receptor antagonists), as well as in patients with accompanying renal impairment, heart failure, and/or renal tubular acidosis associated with diabetes. ${ }^{101,102}$ Additionally, a dramatic increase ( $\sim$ seven-fold) in the risk of hyperkalemia-associated hospitalizations was reported in patients on concomitant therapy of ARBs or ACEIs and trimethoprim-sulfamethoxazole in elderly patients, suggesting the use of alternative antibiotic therapy in this population. ${ }^{103}$

As with many other drugs that posses a vasodilating effect, ARBs should be used with caution in patients with aortic or mitral stenosis and obstructive hypertrophic cardiomyopathy. In long-term studies, ARBs did not appear to affect concentrations of fasting serum glucose, fasting triglycerides, serum uric acid, urinary uric acid secretion, or total cholesterol. ${ }^{104,105}$ ARBs have been extensively employed in patients with unilateral renal stenosis without any secondary effects on renovascular hypertension. ${ }^{101,102}$

In a recent meta-analysis of randomized controlled trials of ARBs, Sipahi et al reported that ARBs are associated with a modestly increased risk of new cancer diagnosis (7.2\% vs $6.0 \%$; risk ratio $1.08 ; 95 \% \mathrm{CI} 1.01-1.15 ; P=0.016) .{ }^{106}$ Undoubtedly, this study received considerable attention, as the possibility that ARBs might increase the risk for cancer is of great concern. ${ }^{107}$ Importantly, the authors of the study as well as many critics acknowledge the limitations of the analysis, which was based on a post hoc analysis of an incomplete database and included trials that were not designed to explore cancer outcomes. ${ }^{108}$ Despite the limitations, the study of Sipahi et al raises several concerns that have important clinical relevance, and their findings warrant further investigations to draw conclusions about the exact risk of cancer associated with the overall class of ARBs and/or particular members of this class. ${ }^{109}$

Very few drug-drug interactions of clinical importance have been noted with ARBs. ${ }^{52,100,110}$ These observations were confirmed by in vitro screening studies with human hepatic cytochrome P450 (CYP) enzymes, indicating negligible inhibitory potential of these drugs. ${ }^{111}$ In addition, neither induction nor inhibition of CYP isoenzymes was observed with valsartan. ${ }^{100}$ Likewise, nonsignificant interactions were observed between irbesartan and CYP2C9 substrates such as tolbutamide, warfarin, and nifedipine. ${ }^{12}$

\section{Pharmacokinetic and pharmacodynamic properties of various $A T$, receptor antagonists}

It is well known that pharmacokinetic profiles of drugs can be modified by age. ${ }^{113}$ For example, changes in the body composition (eg, lean body mass, body water, and fat) can influence drug distribution and half-life without substantial changes in drug absorption. ${ }^{14,115}$ In patients with chronic diseases that are often common in the elderly, plasma albumin concentrations may be decreased, resulting in elevated concentrations of free acidic drugs. ${ }^{116}$ In addition, the level of plasma $\alpha$-1-acid glycoprotein, a key plasma protein responsible for binding and transport of many drugs, is also increased in several conditions, including cardiovascular, kidney, liver, inflammatory, and central nervous system disorders. ${ }^{117}$ Increased bioavailability and prolonged half-life of drugs in aging patients can also be reasoned by decreased intestinal and hepatic metabolism of drugs, as well as decreased renal elimination of metabolites and parent compounds.

The main pharmacokinetic properties of currently available ARBs are summarized in Table 2. Telmisartan is a highly lipophilic drug with a long plasma half-life (20-38 h) and large 


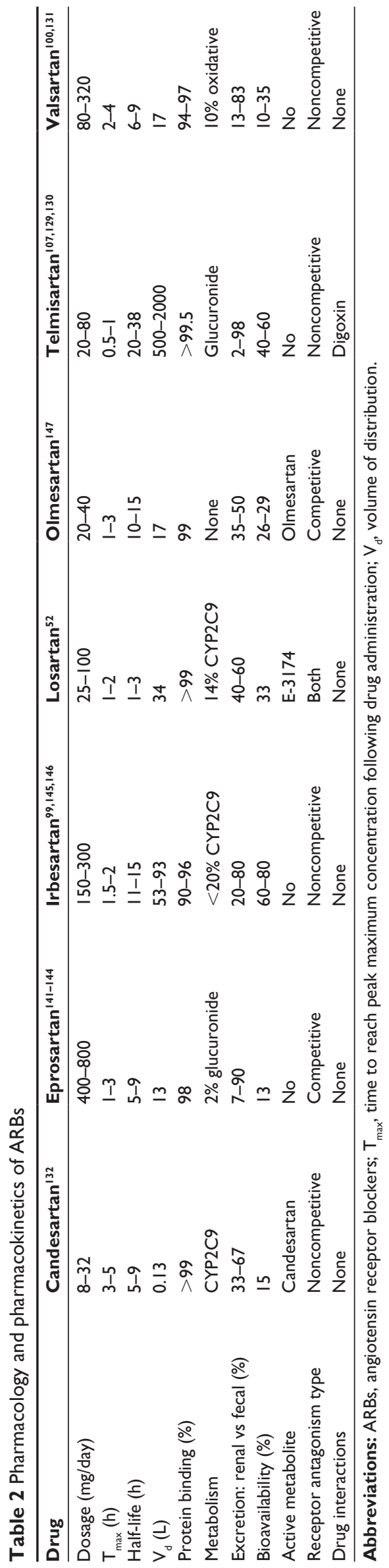

volume of distribution $(7 \mathrm{~L} / \mathrm{kg})$. In contrast, candesartan has a very small volume of distribution $(0.13 \mathrm{~L} / \mathrm{kg})$, indicating restrictive protein binding of the drug and limited tissue distribution. Among all of the ARBs, only losartan, candesartan, and irbesartan are metabolized by CYP isoenzymes. ${ }^{118}$ Approximately $14 \%$ of a given dose of losartan is converted into the free carboxylic acid form EXP3174, an active metabolite of the parent drug with noncompetitive/insurmountable antagonistic activity ${ }^{102}$ Irbesartan is mainly metabolized by CYP2C9 and CYP3A4, and it undergoes glucuronidation. ${ }^{99}$ Valsartan undergoes an oxidative biotransformation to an active metabolite valerly-4-hydroxy-valsartan. ${ }^{119}$

A number of ARBs (eg, eprosartan, irbesartan, and telmisartan) undergo phase II metabolic transformation through acyl glucuronidation in the liver and gastrointestinal system. ${ }^{120,121}$ Glucuronides are excreted by urine and bile, and in the latter case the conjugates are cleaved by bacterial enzymes, leading to liberation of parent compounds or metabolites in the gastrointestinal system. Notably, this metabolic pathway may be impaired by deficiency of uridine diphosphate glucuronosyltransferase 1 $\mathrm{A} 1$, which is considered a potential target for polymorphic variations. ${ }^{122} \mathrm{AT}_{1}$ receptor antagonists are largely eliminated by biliary excretion, although losartan and olmesartan show more substantial renal excretion. Average elimination time of the $\mathrm{AT}_{1}$ receptor blockers is between 5 and $9 \mathrm{~h}$, except losartan, which has the shortest plasma elimination half-life of 1-3 h, and telmisartan, which has the longest plasma elimination half-life of $\sim 24$ h..$^{52,100,107,123,124}$ In general, duration of action of receptor antagonists depends on the rate of their dissociation from the target receptor, which is the case for ARBs as well. All of the ARBs are very effective with once-daily administration, although losartan and eprosartan may provide better 24-h effects when given twice daily.

The area under the plasma concentration-time curve for a number of ARBs (ie, candesartan, eprosartan, irbesartan, olmesartan, and valsartan but not telmisartan) has been shown to increase in the elderly compared with a younger population. ${ }^{121,125-129}$ Nevertheless, the recommended starting dose for most $\mathrm{AT}_{1}$ receptor antagonists (candesartan, eprosartan, irbesartan, losartan, olmesartan) has not been changed in the elderly, which is explained by possible decreased activity of circulating RAAS. It has been demonstrated that patients with moderate hepatic impairment have increased plasma concentrations of most $\mathrm{AT}_{1}$ receptor antagonists, which may require dose adjustments in individual patients, depending on tolerability and response to the drug. ${ }^{105}$ The recommended maximal daily dose of ARBs for patients with moderate hepatic impairment should not exceed $12 \mathrm{mg}$ for candesartan, $20 \mathrm{mg}$ for olmesartan, $40 \mathrm{mg}$ for telmisartan, or $80 \mathrm{mg}$ for 
valsartan. ${ }^{130-133}$ In addition, patients with portal hypertension and liver cirrhosis should only be treated with irbesartan. ${ }^{134}$ As renal elimination is not a major route of excretion for most $\mathrm{AT}_{1}$ receptor antagonists, dose adjustments are usually not required for patients with renal impairment, although lower starting doses are typically used for most patients. Importantly, careful monitoring of renal function is vital after starting ARBs in patients with pre-existing renal impairment. ${ }^{101,135,136}$

\section{Summary and conclusion}

ARBs represent a contemporary class of drugs often used for the treatment of elevated arterial blood pressure in the elderly population, both as monotherapy or in combination with other antihypertensive agents. Although current hypertension guidelines recommend thiazide diuretics as first-line therapy for most patients with hypertension in the absence of a compelling indication, data are now available supporting the use of ARBs as a first-line agent, and it is likely that they will be included as an option for initial management when the new JNC 8 guidelines are released. ${ }^{13,17,137,138}$ In addition to hypertension, ARBs are also recommended as a first-line agent in patients with type 2 diabetes with microalbuminuria or nephropathy. ${ }^{17,139}$ In patients with high arterial blood pressure and heart failure, ARBs are recommended only when ACEIs are not tolerated. ${ }^{140}$ They are also recommended for elderly patients with hypertension and left ventricular hypertrophy, as they have been found to be superior to $\beta$-blocker-based regimens in such high-risk subjects and have a better profile for stroke prevention. ${ }^{87}$ Due to the fact that ARBs are very well tolerated, may be dosed once daily, and have few drug-drug interactions, these agents are an important alternative to other blood pressure-lowering medications. The main disadvantage of ARBs is their cost, as they are typically the most expensive group of blood pressure-lowering agents. However, with the approval of generic losartan and other generic agents in future, it is likely that the use of ARBs as first-line therapy, particularly in the elderly, will continue to grow.

\section{Disclosure}

The authors report no conflicts of interest in this work.

\section{References}

1. Elliott WJ. Management of hypertension in the very elderly patient. Hypertension. 2004;44(6):800-804.

2. Kearney PM, Whelton M, Reynolds K, Muntner P, Whelton PK, He J. Global burden of hypertension: analysis of worldwide data. Lancet. 2005;365(9455):217-223.

3. Vasan RS, Beiser A, Seshadri S, et al. Residual lifetime risk for developing hypertension in middle-aged women and men: The Framingham Heart Study. JAMA. 2002;287(8):1003-1010.
4. Lakatta EG. Arterial and cardiac aging: major shareholders in cardiovascular disease enterprises: Part III: cellular and molecular clues to heart and arterial aging. Circulation. 2003;107(3):490-497.

5. Beckett NS, Peters R, Fletcher AE, et al. Treatment of hypertension in patients 80 years of age or older. $N$ Engl J Med. 2008;358(18):1887-1898.

6. Staessen JA, Fagard R, Thijs L, et al. Randomised double-blind comparison of placebo and active treatment for older patients with isolated systolic hypertension. The Systolic Hypertension in Europe (Syst-Eur) Trial Investigators. Lancet. 1997;350(9080): $757-764$

7. Dahlof B, Lindholm LH, Hansson L, Schersten B, Ekbom T, Wester PO. Morbidity and mortality in the Swedish trial in old patients with hypertension (STOP-hypertension). Lancet. 1991;338(8778): 1281-1285.

8. Medical Research Council European trial of chorion villus sampling. MRC working party on the evaluation pf chorion villus sampling. Lancet. 1991;337(8756):1491-1499.

9. SHEP Cooperative Research Group. Prevention of stroke by antihypertensive drug treatment in older persons with isolated systolic hypertension. Final results of the Systolic Hypertension in the Elderly Program (SHEP). JAMA. 1991;265(24):3255-3264.

10. Israili $\mathrm{ZH}$, Hall WD. ACE inhibitors. Differential use in elderly patients with hypertension. Drugs Aging. 1995;7(5):355-371.

11. Svanborg A. Age-related changes in cardiac physiology. Can they be postponed or treated by drugs? Drugs Aging. 1997;10(6):463-472.

12. Cleophas TJ, van Marum R. Age-related decline in autonomic control of blood pressure: implications for the pharmacological management of hypertension in the elderly. Drugs Aging. 2003;20(5):313-319.

13. Chobanian AV, Bakris GL, Black HR, et al. Seventh report of the Joint National Committee on Prevention, Detection, Evaluation, and Treatment of High Blood Pressure. Hypertension. 2003;42(6):1206-1252.

14. Mancia G, de Backer G, Dominiczak A, et al. 2007 Guidelines for the management of arterial hypertension: the task force for the management of arterial hypertension of the European Society of Hypertension (ESH) and of the European Society of Cardiology (ESC). Eur Heart J. 2007; 28(12):1462-1536.

15. Kalra S, Kalra B, Agrawal N. Combination therapy in hypertension: an update. Diabetol Metab Syndr. 2010;2(1):44.

16. Wright JM, Lee CH, Chambers GK. Systematic review of antihypertensive therapies: does the evidence assist in choosing a first-line drug? CMAJ. 1999;161(1):25-32.

17. Chobanian AV, Bakris GL, Black HR, et al. The seventh report of the Joint National Committee on Prevention, Detection, Evaluation, and Treatment of High Blood Pressure: the JNC 7 report. JAMA. 2003; 289(19):2560-2572.

18. Ogihara T, Rakugi H. Hypertension in the elderly: a Japanese perspective. Drugs Aging. 2005;22(4):297-314.

19. Haller H. Effective management of hypertension with dihydropyridine calcium channel blocker-based combination therapy in patients at high cardiovascular risk. Int J Clin Pract. 2008;62(5):781-790.

20. Hilleman DE, Lucas BD Jr. Angiotensin-converting enzyme inhibitors and stroke risk: benefit beyond blood pressure reduction? Pharmacotherapy. 2004;24(8):1064-1076.

21. Bangalore S, Messerli FH, Kostis JB, Pepine CJ. Cardiovascular protection using beta-blockers: a critical review of the evidence. J Am Coll Cardiol. 2007;50(7):563-572.

22. Fleg JL, Aronow WS, Frishman WH. Cardiovascular drug therapy in the elderly: benefits and challenges. Nat Rev Cardiol. 2010;1-16.

23. Werner C, Baumhakel M, Teo KK, et al. RAS blockade with ARB and ACE inhibitors: current perspective on rationale and patient selection. Clin Res Cardiol. 2008;97(7):418-431.

24. Weber M. Achieving blood pressure goals: should angiotensin II receptor blockers become first-line treatment in hypertension? J Hypertens Suppl. 2009;27(5):S9-S14

25. Cooney D, Pascuzzi K. Polypharmacy in the elderly: focus on drug interactions and adherence in hypertension. Clin Geriatr Med. 2009; 25(2):221-233. 
26. Covic A, Gusbeth-Tatomir P. The role of the renin-angiotensinaldosterone system in renal artery stenosis, renovascular hypertension, and ischemic nephropathy: diagnostic implications. Prog Cardiovasc Dis. 2009;52(3):204-208.

27. Turgut F, Balogun RA, Abdel-Rahman EM. Renin-angiotensinaldosterone system blockade effects on the kidney in the elderly: benefits and limitations. Clin J Am Soc Nephrol. 2010;5(7):1330-1339.

28. Siragy HM, Carey RM. Role of the intrarenal renin-angiotensin-aldosterone system in chronic kidney disease. Am J Nephrol. 2010;31(6): 541-550.

29. Belmin J, Levy BI, Michel JB. Changes in the renin-angiotensinaldosterone axis in later life. Drugs Aging. 1994;5(5):391-400.

30. Tsunoda K, Abe K, Goto T, et al. Effect of age on the renin-angiotensinaldosterone system in normal subjects: simultaneous measurement of active and inactive renin, renin substrate, and aldosterone in plasma. $J$ Clin Endocrinol Metab. 1986;62(2):384-389.

31. Schiffrin EL, Touyz RM. Multiple actions of angiotensin II in hypertension: benefits of AT1 receptor blockade. J Am Coll Cardiol. 2003;42(5):911-913.

32. Kaschina E, Unger T. Angiotensin AT1/AT2 receptors: regulation, signalling and function. Blood Press. 2003;12(2):70-88

33. Benigni A, Cassis P, Remuzzi G. Angiotensin II revisited: new roles in inflammation, immunology and aging. EMBO Mol Med. 2010;2(7): 247-257.

34. Yamamoto R, Akazawa H, Ito K, et al. Angiotensin II type 1a receptor signals are involved in the progression of heart failure in MLP-deficient mice. Circ J. 2007;71(12):1958-1964.

35. Sasaki T, Kuzuya M, Nakamura K, et al. AT1 blockade attenuates atherosclerotic plaque destabilization accompanied by the suppression of cathepsin S activity in apoE-deficient mice. Atherosclerosis. 2010; 210(2):430-437.

36. Ehrlich JR, Nattel S. Novel approaches for pharmacological management of atrial fibrillation. Drugs. 2009;69(7):757-774.

37. Tadevosyan A, Maguy A, Villeneuve LR, et al. Nuclear-delimited angiotensin receptor-mediated signaling regulates cardiomyocyte gene expression. J Biol Chem. 2010;285(29):22338-22349.

38. Billet S, Aguilar F, Baudry C, Clauser E. Role of angiotensin II AT1 receptor activation in cardiovascular diseases. Kidney Int. 2008;74(11) 1379-1384.

39. Skeggs LT Jr, Kahn JR, Lentz K, Shumway NP. The preparation, purification, and amino acid sequence of a polypeptide renin substrate. $J$ Exp Med. 1957;106(3):439-453.

40. Katragadda S, Arora RR. Role of angiotensin-converting enzyme inhibitors in vascular modulation: beyond the hypertensive effects. $\mathrm{Am}$ J Ther. 2010;17(1):e11-e23.

41. Morath C, Schmied B, Mehrabi A, et al. Angiotensin-converting enzyme inhibitors and angiotensin II type 1 receptor blockers after renal transplantation. Clin Transplant. 2009;23 Suppl 21:33-36.

42. Brown NJ, Vaughan DE. Angiotensin-converting enzyme inhibitors Circulation. 1998;97(14):1411-1420.

43. Israili ZH, Hall WD. Cough and angioneurotic edema associated with angiotensin-converting enzyme inhibitor therapy. A review of the literature and pathophysiology. Ann Intern Med. 1992;117(3) 234-242.

44. Woo KS, Nicholls MG. High prevalence of persistent cough with angiotensin converting enzyme inhibitors in Chinese. Br J Clin Pharmacol. 1995;40(2):141-144

45. Os I, Bratland B, Dahlof B, Gisholt K, Syvertsen JO, Tretli S. Female sex as an important determinant of lisinopril-induced cough. Lancet 1992;339(8789):372

46. Hoover T, Lippmann M, Grouzmann E, Marceau F, Herscu P. Angiotensin converting enzyme inhibitor induced angio-oedema: a review of the pathophysiology and risk factors. Clin Exp Allergy. 2010;40(1):50-61.

47. Brown NJ, Ray WA, Snowden M, Griffin MR. Black Americans have an increased rate of angiotensin converting enzyme inhibitor-associated angioedema. Clin Pharmacol Ther. 1996;60(1):8-13.
48. Slater EE, Merrill DD, Guess HA, et al. Clinical profile of angioedema associated with angiotensin converting-enzyme inhibition. JAMA. 1988;260(7):967-970.

49. Tomlinson B, Young RP, Chan JC, Chan TY, Critchley JA. Pharmacoepidemiology of ACE inhibitor-induced cough. Drug Saf. 1997;16(2):150-151.

50. McInnes GT, O’Kane KP, Istad H, Keinanen-Kiukaanniemi S, van Mierlo HF. Comparison of the AT1-receptor blocker, candesartan cilexetil, and the ACE inhibitor, lisinopril, in fixed combination with low dose hydrochlorothiazide in hypertensive patients. J Hum Hypertens. 2000;14(4):263-269.

51. Goa KL, Wagstaff AJ. Losartan potassium: a review of its pharmacology, clinical efficacy and tolerability in the management of hypertension. Drugs. 1996;51(5):820-845.

52. Simpson KL, McClellan KJ. Losartan: a review of its use, with special focus on elderly patients. Drugs Aging. 2000;16(3):227-250.

53. Unger T. Pharmacology of AT1-receptor blockers. Blood Press Suppl. $2001 ;(3): 5-10$.

54. Turnbull F; Blood Pressure Lowering Treatment Trialists' Collaboration. Effects of different blood-pressure-lowering regimens on major cardiovascular events: results of prospectively-designed overviews of randomised trials. Lancet. 2003;362(9395):1527-1535.

55. Law MR, Morris JK, Wald NJ. Use of blood pressure lowering drugs in the prevention of cardiovascular disease: meta-analysis of 147 randomised trials in the context of expectations from prospective epidemiological studies. BMJ. 2009;338:b1665. Doi: 10.1136/bmj.b1665.

56. Gradman AH, Papademetriou V. Combined renin-angiotensinaldosterone system inhibition in patients with chronic heart failure secondary to left ventricular systolic dysfunction. Am Heart J. 2009; 157(Suppl 6):S17-S23.

57. Francis GS, Cohn JN, Johnson G, Rector TS, Goldman S, Simon A Plasma norepinephrine, plasma renin activity, and congestive heart failure. Relations to survival and the effects of therapy in V-HeFT II. The V-HeFT VA Cooperative Studies Group. Circulation. 1993;87 (Suppl 6):VI40-VI48.

58. Riegger GA, Bouzo H, Petr P, et al. Improvement in exercise tolerance and symptoms of congestive heart failure during treatment with candesartan cilexetil. Symptom, Tolerability, Response to Exercise Trial of Candesartan Cilexetil in Heart Failure (STRETCH) Investigators Circulation. 1999;100(22):2224-2230.

59. Cohn JN. Rationale for angiotensin II receptor blocker therapy in chronic heart failure. J Renin Angiotensin Aldosterone Syst. 2000; 1(Suppl 2):S38-S40.

60. Maggioni AP, Anand I, Gottlieb SO, Latini R, Tognoni G, Cohn JN. Effects of valsartan on morbidity and mortality in patients with heart failure not receiving angiotensin-converting enzyme inhibitors. $J \mathrm{Am}$ Coll Cardiol. 2002;40(8):1414-1421.

61. Pitt B, Segal R, Martinez FA, et al. Randomised trial of losartan versus captopril in patients over 65 with heart failure (Evaluation of Losartan in the Elderly Study, ELITE). Lancet. 1997;349(9054):747-752.

62. Pitt B, Poole-Wilson PA, Segal R, et al. Effect of losartan compared with captopril on mortality in patients with symptomatic heart failure: randomised trial-the Losartan Heart Failure Survival Study ELITE II. Lancet. 2000;355(9215):1582-1587.

63. Cohn JN, Tognoni G; Valsartan Heart Failure Trial Investigators. A randomized trial of the angiotensin-receptor blocker valsartan in chronic heart failure. N Engl J Med. 2001;345(23):1667-1675.

64. Dickstein K. ELITE II and Val-HeFT are different trials: together what do they tell us? Curr Control Trials Cardiovasc Med. 2001;2(5) 240-243.

65. Pfeffer MA, Swedberg K, Granger CB, et al. Effects of candesartan on mortality and morbidity in patients with chronic heart failure: the CHARM-Overall programme. Lancet. 2003;362(9386):759-766.

66. Granger CB, McMurray JJ, Yusuf S, et al. Effects of candesartan in patients with chronic heart failure and reduced left-ventricular systolic function intolerant to angiotensin-converting-enzyme inhibitors: the CHARM-alternative trial. Lancet. 2003;362(9386):772-776. 
67. McMurray JJ, Ostergren J, Swedberg K, et al. Effects of candesartan in patients with chronic heart failure and reduced left-ventricular systolic function taking angiotensin-converting-enzyme inhibitors: the CHARM-Added trial. Lancet. 2003;362(9386):767-771.

68. Yusuf S, Pfeffer MA, Swedberg K, et al. Effects of candesartan in patients with chronic heart failure and preserved left-ventricular ejection fraction: the CHARM-Preserved Trial. Lancet. 2003;362(9386):777-781.

69. Dickstein K, Kjekshus J; OPTIMAAL Steering Committee of the OPTIMAAL Study Group. Effects of losartan and captopril on mortality and morbidity in high-risk patients after acute myocardial infarction: the OPTIMAAL randomised trial. Optimal trial in myocardial infarction with angiotensin II antagonist losartan. Lancet. 2002;360(9335):752-760.

70. Pfeffer MA, McMurray JJ, Velazquez EJ, et al. Valsartan, captopril, or both in myocardial infarction complicated by heart failure, left ventricular dysfunction, or both. N Engl J Med. 2003;349(20):1893-1906.

71. Yusuf S, Teo KK, Pogue J, et al. Telmisartan, ramipril, or both in patients at high risk for vascular events. $N$ Engl J Med. 2008;358(15): 1547-1559.

72. Yusuf S, Teo K, Anderson C, et al. Effects of the angiotensin-receptor blocker telmisartan on cardiovascular events in high-risk patients intolerant to angiotensin-converting enzyme inhibitors: a randomised controlled trial. Lancet. 2008;372(9644):1174-1183.

73. Unger J, Parkin CG. Type 2 diabetes: an expanded view of pathophysiology and therapy. Postgrad Med. 2010;122(3):145-157.

74. UK Prospective Diabetes Study Group. Tight blood pressure control and risk of macrovascular and microvascular complications in type 2 diabetes: UKPDS 38. BMJ. 1998;317(7160):703-713.

75. Ruilope LM. Angiotensin receptor blockers: RAAS blockade and renoprotection. Curr Med Res Opin. 2008;24(5):1285-1293.

76. Siamopoulos KC, Kalaitzidis RG. Inhibition of the renin-angiotensin system and chronic kidney disease. Int Urol Nephrol. 2008;40(4): 1015-1025.

77. Parving HH, Lehnert H, Brochner-Mortensen J, Gomis R, Andersen S, Arner P. The effect of irbesartan on the development of diabetic nephropathy in patients with type 2 diabetes. N Engl J Med. 2001;345(12): 870-878.

78. Lewis EJ, Hunsicker LG, Clarke WR, et al. Renoprotective effect of the angiotensin-receptor antagonist irbesartan in patients with nephropathy due to type 2 diabetes. N Engl J Med. 2001;345(12):851-860.

79. Brenner BM, Cooper ME, de Zeeuw D, et al. Effects of losartan on renal and cardiovascular outcomes in patients with type 2 diabetes and nephropathy. N Engl J Med. 2001;345(12):861-869.

80. Viberti G, Wheeldon NM; MicroAlbuminuria Reduction With VALsartan (MARVAL) Study Investigators. Microalbuminuria reduction with valsartan in patients with type 2 diabetes mellitus: a blood pressure-independent effect. Circulation. 2002;106(6):672-678.

81. Scheen AJ. Prevention of type 2 diabetes mellitus through inhibition of the Renin-Angiotensin system. Drugs. 2004;64(22):2537-2565.

82. Derosa G, Cicero AF, D'Angelo A, et al. Telmisartan and irbesartan therapy in type 2 diabetic patients treated with rosiglitazone: effects on insulin-resistance, leptin and tumor necrosis factor-alpha. Hypertens Res. 2006;29(11):849-856.

83. Nagel JM, Tietz AB, Goke B, Parhofer KG. The effect of telmisartan on glucose and lipid metabolism in nondiabetic, insulin-resistant subjects. Metabolism. 2006;55(9):1149-1154.

84. Wiernsperger N. Vascular defects in the aetiology of peripheral insulin resistance in diabetes. A critical review of hypotheses and facts. Diabetes Metab Rev. 1994;10(3):287-307.

85. Elliott WJ, Meyer PM. Incident diabetes in clinical trials of antihypertensive drugs: a network meta-analysis. Lancet. 2007;369(9557): 201-207.

86. American Diabetes Association. Standards of medical care in diabetes-2010. Diabetes Care. 2010;33 Suppl 1:S11-S61.

87. Dahlof B, Devereux RB, Kjeldsen SE, et al. Cardiovascular morbidity and mortality in the Losartan Intervention For Endpoint reduction in hypertension study (LIFE): a randomised trial against atenolol. Lancet. 2002;359(9311):995-1003.
88. Lindholm LH, Ibsen H, Dahlof B, et al. Cardiovascular morbidity and mortality in patients with diabetes in the Losartan Intervention For Endpoint reduction in hypertension study (LIFE): a randomised trial against atenolol. Lancet. 2002;359(9311):1004-1010.

89. Devereux RB, Lyle PA. Losartan for the treatment of hypertension and left ventricular hypertrophy: the Losartan Intervention For Endpoint reduction in hypertension (LIFE) study. Expert Opin Pharmacother. 2004;5(11):2311-2320.

90. Julius S, Alderman MH, Beevers G, et al. Cardiovascular risk reduction in hypertensive black patients with left ventricular hypertrophy: the LIFE study. J Am Coll Cardiol. 2004;43(6):1047-1055.

91. Lithell H, Hansson L, Skoog I, et al. The Study on Cognition and Prognosis in the Elderly (SCOPE): principal results of a randomized double-blind intervention trial. J Hypertens. 2003;21(5):875-886.

92. Papademetriou V, Farsang C, Elmfeldt D, et al. Stroke prevention with the angiotensin II type 1-receptor blocker candesartan in elderly patients with isolated systolic hypertension: the Study on Cognition and Prognosis in the Elderly (SCOPE). J Am Coll Cardiol. 2004;44(6): 1175-1180.

93. Chobanian AV. Clinical practice. Isolated systolic hypertension in the elderly. N Engl J Med. 2007;357(8):789-796.

94. Julius S, Kjeldsen SE, Weber M, et al. Outcomes in hypertensive patients at high cardiovascular risk treated with regimens based on valsartan or amlodipine: the VALUE randomised trial. Lancet. 2004;363(9426):2022-2031

95. Lindholm LH, Persson M, Alaupovic P, Carlberg B, Svensson A, Samuelsson O. Metabolic outcome during 1 year in newly detected hypertensives: results of the Antihypertensive Treatment and Lipid Profile in a North of Sweden Efficacy Evaluation (ALPINE study). J Hypertens. 2003;21(8):1563-1574.

96. McKelvie RS, Yusuf S, Pericak D, et al. Comparison of candesartan, enalapril, and their combination in congestive heart failure: randomized evaluation of strategies for left ventricular dysfunction (RESOLVD) pilot study. The RESOLVD Pilot Study Investigators. Circulation. 1999;100(10):1056-1064.

97. Hall WD, Montoro R, Littlejohn T, Jain A, Feliciano N, Zheng H. Efficacy and tolerability of valsartan in combination with hydrochlorothiazide in essential hypertension. Clin Drug Investig. 1998;16(3): 203-210.

98. Critchley LA. Hypotension, subarachnoid block and the elderly patient. Anaesthesia. 1996;51(12):1139-1143.

99. Gillis JC, Markham A. Irbesartan. A review of its pharmacodynamic and pharmacokinetic properties and therapeutic use in the management of hypertension. Drugs. 1997;54(6):885-902.

100. Markham A, Goa KL. Valsartan. A review of its pharmacology and therapeutic use in essential hypertension. Drugs. 1997;54(2):299-311.

101. Weir MR. Are drugs that block the renin-angiotensin system effective and safe in patients with renal insufficiency? Am J Hypertens. 1999; 12(12 Pt 3):195S-203S.

102. Burnier M, Brunner HR. Angiotensin II receptor antagonists. Lancet. 2000;355(9204):637-645.

103. Antoniou T, Gomes T, Juurlink DN, Loutfy MR, Glazier RH, Mamdani MM. Trimethoprim-sulfamethoxazole-induced hyperkalemia in patients receiving inhibitors of the renin-angiotensin system: a population-based study. Arch Intern Med. 2010;170(12):1045-1049.

104. Puig JG, Mateos F, Buno A, Ortega R, Rodriguez F, Dal-Re R. Effect of eprosartan and losartan on uric acid metabolism in patients with essential hypertension. J Hypertens. 1999;17(7):1033-1039.

105. Csajka C, Buclin T, Brunner HR, Biollaz J. Pharmacokineticpharmacodynamic profile of angiotensin II receptor antagonists. Clin Pharmacokinet. 1997;32(1):1-29.

106. Sipahi I, Debanne SM, Rowland DY, Simon DI, Fang JC. Angiotensinreceptor blockade and risk of cancer: meta-analysis of randomised controlled trials. Lancet Oncol. 2010;11(7):627-636.

107. Goldstein MR, Mascitelli L, Pezzetta F. Angiotensin-receptor blockade, cancer, and concerns. Lancet Oncol. 2010;11:819.

108. Böhm M, Laufs U, Pfreundschuh M. Comment on: Angiotensinreceptor blockade and risk of cancer: meta-analysis of randomised controlled trials. Lancet Oncol. 2010;11:818. 
109. Meredith P.A., McInnes G.T. Comment on: Angiotensinreceptor blockade and risk of cancer: meta-analysis of randomised controlled trials. Lancet Oncol. 2010;11:819.

110. Sharpe M, Jarvis B, Goa KL. Telmisartan: a review of its use in hypertension. Drugs. 2001;61(10):1501-1529.

111. Taavitsainen P, Kiukaanniemi K, Pelkonen O. In vitro inhibition screening of human hepatic P450 enzymes by five angiotensin-II receptor antagonists. Eur J Clin Pharmacol. 2000;56(2):135-140.

112. Marino MR, Vachharajani NN. Drug interactions with irbesartan. Clin Pharmacokinet. 2001;40(8):605-614.

113. Cody RJ. Physiological changes due to age. Implications for drug therapy of congestive heart failure. Drugs Aging. 1993;3(4):320-334.

114. Morgan DJ, Bray KM. Lean body mass as a predictor of drug dosage. Implications for drug therapy. Clin Pharmacokinet. 1994;26(4): 292-307.

115. Turnheim K. Drug dosage in the elderly. Is it rational? Drugs Aging. 1998;13(5):357-379.

116. Fu A, Nair KS. Age effect on fibrinogen and albumin synthesis in humans. Am J Physiol. 1998;275(6 Pt 1):E1023-E1030.

117. Israili ZH, Dayton PG. Human alpha-1-glycoprotein and its interactions with drugs. Drug Metab Rev. 2001;33(2):161-235.

118. Unger T, Kaschina E. Drug interactions with angiotensin receptor blockers: a comparison with other antihypertensives. Drug Saf. 2003; 26(10):707-720.

119. Waldmeier F, Flesch G, Muller P, et al. Pharmacokinetics, disposition and biotransformation of [14C]-radiolabelled valsartan in healthy male volunteers after a single oral dose. Xenobiotica. 1997;27(1):59-71.

120. Ruilope L, Jager B. Eprosartan for the treatment of hypertension. Expert Opin Pharmacother. 2003;4(1):107-114.

121. Tenero DM, Martin DE, Miller AK, et al. Effect of age and gender on the pharmacokinetics of eprosartan. Br J Clin Pharmacol. 1998;46(3): 267-270.

122. Uchida S, Watanabe H, Nishio S, et al. Altered pharmacokinetics and excessive hypotensive effect of candesartan in a patient with the CYP2C91/3 genotype. Clin Pharmacol Ther. 2003;74(5) 505-508.

123. Mallion J, Siche J, Lacourciere Y. ABPM comparison of the antihypertensive profiles of the selective angiotensin II receptor antagonists telmisartan and losartan in patients with mild-to-moderate hypertension. J Hum Hypertens. 1999;13(10):657-664.

124. White WB, Anwar YA, Mansoor GA, Sica DA. Evaluation of the 24-hour blood pressure effects of eprosartan in patients with systemic hypertension. Am J Hypertens. 2001;14(12):1248-1255.

125. Hubner R, Hogemann AM, Sunzel M, Riddell JG. Pharmacokinetics of candesartan after single and repeated doses of candesartan cilexetil in young and elderly healthy volunteers. JHum Hypertens. 1997;11 Suppl2: S19-S25.

126. Sioufi A, Marfil F, Jaouen A, et al. The effect of age on the pharmacokinetics of valsartan. Biopharm Drug Dispos. 1998;19(4):237-244.

127. Vachharajani NN, Shyu WC, Smith RA, Greene DS. The effects of age and gender on the pharmacokinetics of irbesartan. Br J Clin Pharmacol. 1998;46(6):611-613.

128. von Bergmann K, Laeis P, Puchler K, Sudhop T, Schwocho LR, Gonzalez L. Olmesartan medoxomil: influence of age, renal and hepatic function on the pharmacokinetics of olmesartan medoxomil J Hypertens Suppl. 2001;19(1):S33-S40.

129. McClellan KJ, Markham A. Telmisartan. Drugs. 1998;56(6): 1039-1044; discussion 1045-1046.

Patient Related Outcome Measures

\section{Publish your work in this journal}

Patient Related Outcome Measures is an international, peer-reviewed, open access journal focusing on treatment outcomes specifically relevant to patients. All aspects of patient care are addressed within the journal and practitioners from all disciplines are invited to submit their work as well as healthcare researchers and patient support groups. Areas covered will
130. Stangier J, Su CA, Schondorfer G, Roth W. Pharmacokinetics and safety of intravenous and oral telmisartan $20 \mathrm{mg}$ and $120 \mathrm{mg}$ in subjects with hepatic impairment compared with healthy volunteers. J Clin Pharmacol. 2000;40(12 Pt 1):1355-1364.

131. Thurmann PA. Valsartan: a novel angiotensin type 1 receptor antagonist. Expert Opin Pharmacother. 2000;1(2):337-350.

132. Gleiter $\mathrm{CH}$, Morike KE. Clinical pharmacokinetics of candesartan. Clin Pharmacokinet. 2002;41(1):7-17.

133. Brousil JA, Burke JM. Olmesartan medoxomil: an angiotensin II-receptor blocker. Clin Ther. 2003;25(4):1041-1055.

134. Schepke M, Werner E, Biecker E, et al. Hemodynamic effects of the angiotensin II receptor antagonist irbesartan in patients with cirrhosis and portal hypertension. Gastroenterology. 2001;121(2):389-395.

135. Burnier M. Angiotensin II type 1 receptor blockers. Circulation. 2001; 103(6):904-912.

136. Weir MR. Diabetes and hypertension: how low should you go and with which drugs? Am J Hypertens. 2001;14(5 Pt 2):17S-26S.

137. Cuspidi C, Negri F, Zanchetti A. Angiotensin II receptor blockers and cardiovascular protection: focus on left ventricular hypertrophy regression and atrial fibrillation prevention. Vasc Health Risk Manag. 2008;4(1):67-73.

138. Hanes DS, Weir MR. Usefulness of ARBs and ACE inhibitors in the prevention of vascular dementia in the elderly. Am J Geriatr Cardiol. 2007;16(3):175-182

139. European Society of Hypertension-European Society of Cardiology Guidelines Committee. 2003 European Society of HypertensionEuropean Society of Cardiology guidelines for the management of arterial hypertension. J Hypertens. 2003;21(6):1011-1053.

140. Simko F, Simko J, Fabryova M. ACE-inhibition and angiotensin II receptor blockers in chronic heart failure: pathophysiological consideration of the unresolved battle. Cardiovasc Drugs Ther. 2003;17(3): 287-290.

141. Plosker GL, Foster RH. Eprosartan: a review of its use in the management of hypertension. Drugs. 2000;60(1):177-201.

142. Bottorff MB, Tenero DM. Pharmacokinetics of eprosartan in healthy subjects, patients with hypertension, and special populations. Pharmacotherapy. 1999;19(4 Pt 2):73S-78S.

143. McClellan KJ, Balfour JA. Eprosartan. Drugs. 1998;55(5):713-718; discussion 719-720.

144. Tenero D, Martin D, Chapelsky M, et al. Effect of hepatic disease on the pharmacokinetics and plasma protein binding of eprosartan. Pharmacotherapy. 1998;18(1):42-50.

145. Markham A, Spencer CM, Jarvis B. Irbesartan: an updated review of its use in cardiovascular disorders. Drugs. 2000;59(5):1187-1206.

146. Marino MR, Langenbacher KM, Raymond RH, Ford NF, Lasseter KC. Pharmacokinetics and pharmacodynamics of irbesartan in patients with hepatic cirrhosis. J Clin Pharmacol. 1998;38(4):347-356.

147. Warner GT, Jarvis B. Olmesartan medoxomil. Drugs. 2002;62(9): 1345-1353; discussion 1354-1356.

148. Karamyan VT, Speth RC. Enzymatic pathways of the brain reninangiotensin system: unsolved problems and continuing challenges. Regul Pept. 2007;143(1-3):15-27.

149. Saseen JJ, MacLaughlin EJ. Hypertension. In: eds DiPiro JT, Talbert RL, Yee GR, Matzke GR, Wells BG, Posey LM. Pharmacotherapy: a Pathophysiologic Approach. 7th ed. McGraw-Hill Companies, Inc.; 2008:139-171.

include: Quality of life scores; Patient satisfaction audits; Treatment outcomes that focus on the patient; Research into improving patient outcomes; Hypotheses of interventions to improve outcomes; Short communications that illustrate improved outcomes; Case reports or series that show an improved patient experience; Patient journey descriptions or research. 